\title{
Determination of the anthropometry of processors for designing ergonomically improved dewatered cassava mash (DCM) sieving machine
}

\author{
Abraham Azubuike Ahiakwo *, Jesinta Osere and Ndidi Joy Chijioke-Oke \\ Department of Agricultural Education, School of Vocational Education, Federal College of Education (Tech.) Omoku, \\ Rivers State, Nigeria.
}

Global Journal of Engineering and Technology Advances, 2021, 06(01), 015-025

Publication history: Received on 11 December 2020; revised on 30 December 2020; accepted on 02 January 2021

Article DOI: https://doi.org/10.30574/gjeta.2021.6.1.0110

\begin{abstract}
Traditional dewatered cassava mash sieving device developed by local craftsmen in Nigeria exposes users to workrelated musculoskeletal discomfort (WMSD), among other drawbacks such as low throughput capacity, high energy, and time input. This research seeks to develop an improved manual dewatered cassava mash (DCM) machine which alleviates this exposure as well as enhance productivity. Anthropometric parameters of 150 cassava processors from three senatorial districts of Rivers state were collected and analyzed. From the data of body parts of processors measured, an improved manual DCM machine was developed. The result of the measurement analyzed using t-test and analysis of variance (ANOVA) revealed that there was no statistically significant difference between the male and female parameters measured within a zone and between the three zones investigated. The measured parameters yielded the following mean values for the 5 th, 50 th and $95^{\text {th }}$ percentile of the generated data: elbow height sitting (D) of 15.00, 19.23 and 22.67; lower leg length (E) of 38.80, 44.03 and 48.87, elbow to fingertip (F) of 38.27, 48.23 and 52.43 ; thigh clearance $(\mathrm{H})$ of 9.83, 13.17 and 18.00; hip breadth $(\mathrm{J})$ of 28.33, 32.83 and 42, respectively in centimeters for the three zones. Also, the ergonomic dimensions for a more comfortable posture for the machine were recommended: $72 \mathrm{~cm}$ for machine height, $53 \mathrm{~cm}$ for machine width, $68 \mathrm{~cm}$ for machine length, and a sitting range of $36-50 \mathrm{~cm}$.
\end{abstract}

Keywords: Cassava mash; Sieve; Anthropometry; Cassava processors; Ergonomic

\section{Introduction}

Sieving, a necessary unit operation in the conversion of cassava tuber into garri, is currently executed by garri producers manually with the traditional sieve. In the traditional setting, the operators, especially women and children, sits beside a traditional sieve made of raffia, load a lump of cassava mash on to the sieve, shatters it, and then bends back and forth to shear the mash against the sieve. During the operation, the operator suffers waist pain resulting from the sitting posture, which involves bending and stretching, irritating sensation resulting from friction of rubbing the palm against the sieve with broken lumps of cassava mash [1,2]. The process is adjudged as energy and time consuming and according to $[3,4]$ it takes two hours thirty minutes to sieve $60 \mathrm{~kg}$ of dewatered cassava mash on a traditional sieve of $3 \mathrm{~mm}$ aperture, with energy spent at the rate of 3.17 to $3.52 \mathrm{KJ} / \mathrm{min}$ during the sieving process.

Attempts at breaking through the drudgery involved in traditional sieving process employing motorized sieving machines have not been fully achieved. Over $92 \%$ of garri producers still use the traditional raffia sieve for pulverizing and sifting operation $[4,2]$ with a negligible percentage of motorized sieving machine under trial $[5,6]$.

\footnotetext{
* Corresponding author: Abraham Azubuike Ahiakwo; Phone: 08038778669; E-mail: a.ahiakwo@yahoo.com Department of Agricultural Education, School of Vocational Education, Federal College of Education (Tech.) Omoku, Rivers State, Nigeria. 
Moreover, there has not been empirical data to back up the developmental process of the traditional sieve construction. However, the effect traditional sieves have on the users' comfort level as well as their level of exposure to musculoskeletal discomfort during sieving process was evaluated. As reported by [7] traditional sieve users are at a high risk of developing musculoskeletal disorders on the long run as they were exposed to a discomfort level of $66 \%$ based on a quick ergonomic checklist rating [7]. This justifies the need for ergonomic evaluation of processors, processing devices, and the environment using anthropometric data of users group.

[8] defined anthropometry as the science of measurement that establishes the physical dimension and strength capabilities of the human body for design purposes and body composition [9, 10]. Ergonomics make use of anthropometry to evaluate the fitness of a machine to the human operator. It involves the measurement of the human body parts to evaluate variation in user groups and to accommodate identified variation for a comfortable design. The result, when factored into a design, ensures the fitness and human comfort during operation [9]. Anthropometry has three major principles, which are followed in designing various products depending on the type of product. The first principle is "design for extreme individual," which can be either design for the maximum population commonly referred to as 95th percentile male or design for the minimum population value as commonly referred to as 5 th percentile female [11]. The second principle is "designing for an adjustable range," which put consideration of both 5th female and 95th male to accommodate $90 \%$ of the population. According to [12] anthropometric data for use in engineering design situations are best presented in percentiles. Percentile is a value in the range of a set of data that separates the range into groups.

Ergonomics and anthropometry have recently been used to evaluate most agro-machinery and processing machines. Such evaluation using ergonomic analysis tools have revealed a misfit between human and the machine leading to severe musculoskeletal discomfort and production loss as is in the case of the sieving process. This has been reported in gari frying operation where a call for intervention and modification of the system has been made $[13,14,15]$.

According to [16,17], meeting ergonomic design goals can only be accomplished by considering the potential human user and this cannot be accomplished without the measurement of their body dimensions.

No work has reportedly been done to evaluate sieving process with respect to ergonomic and anthropometry. According to $[13,15]$, because there has been little published work that has focused explicitly upon occupational disorders or ergonomic hazards in agro-processing, technology initiatives that addressed such problems often fail because they do not engage the target users.

According to [18], it is essential to include anthropometry and ergonomic in the design of agro-processing machine early before the start of musculoskeletal injuries which usually begin with the worker experiencing mild discomfort sets in and which when ignored, gradually progresses from aches and pain to actual musculoskeletal injury, such as tendonitis, tenosynovitis, or serious nerve-compression injury like carpal tunnel syndrome [19]. Dewatered cassava mash processors as reported by [7] have acknowledged the feeling of discomfort during the sieving process, and this has been recognized as the body's early warning signs that some attribute of the processors' sieving operation should be changed [20].

It is, therefore, the objective of this research to determine the anthropometry of cassava processors that use the traditional sieve in the three senatorial districts of Rivers State, find out if there is a statistically significant difference in the measured parts of the processor within and between the three zones and to factor-in the anthropometric data into a conceptualized improved DCM sieving machine to initiate a sustainable transformation in the field of cassava processing which will alleviate discomfort and enhance economic gain in cassava farming and processing.

\section{Material and methods}

\subsection{Study Area}

The research project was done in Rivers State of Nigeria. Rivers state has 23 Local Government Areas with three senatorial district, divided into: Rivers east (Zone A), Rivers west senatorial district (Zone B) and Rivers south-east district (Zone C), having a population above 7 million people [21] and covering an area of 11,077km2. Figure $1 \mathrm{a}$, shows the location of Rivers state in Nigerian map while Figure 1b shows the three senatorial zones of Rivers state under consideration. 


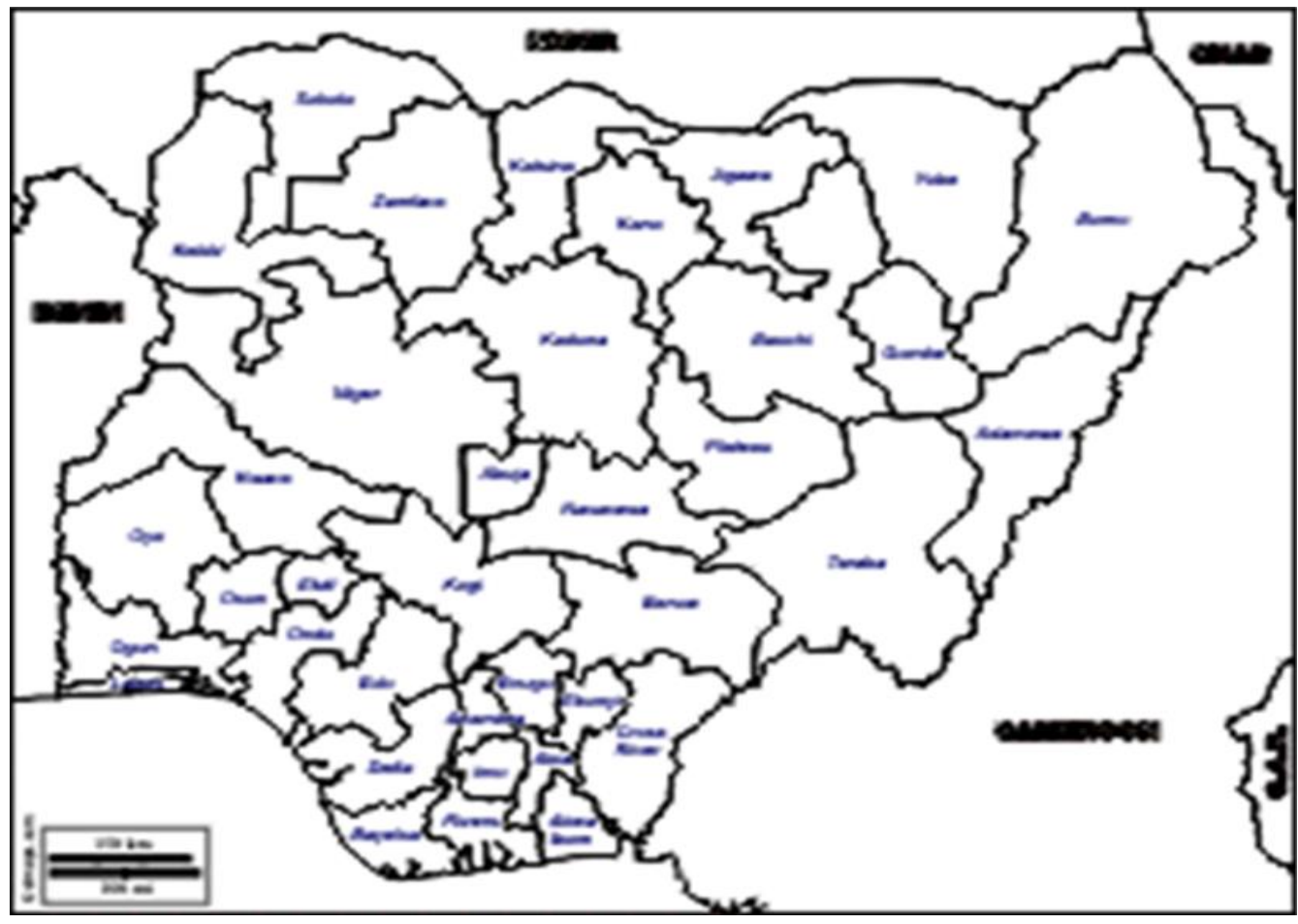

Figure 1a Nigerian of map showing location of Rivers state. Source: [22]

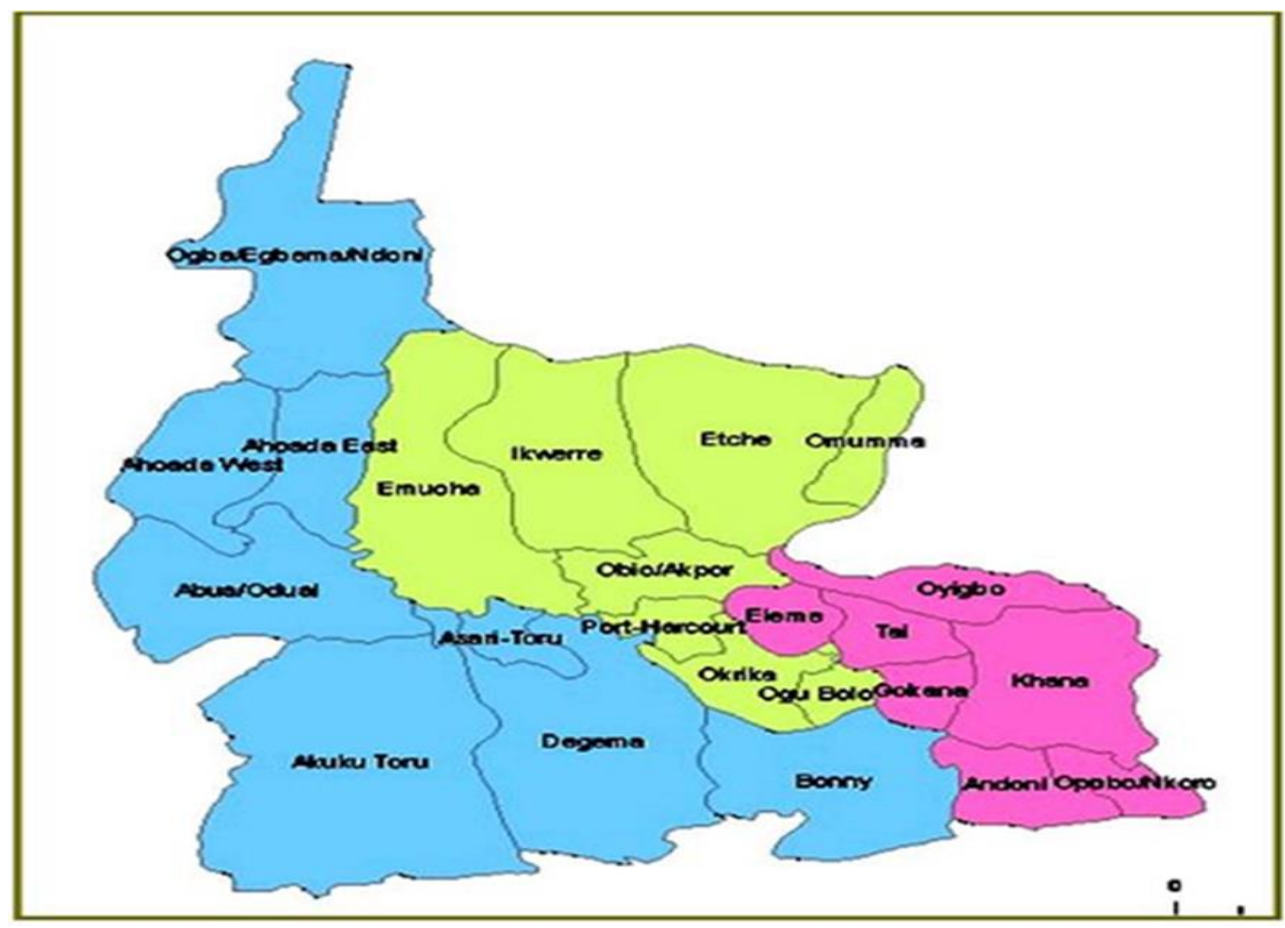

Legend: $\square$ Rivers east, $\square$ Rivers west, $\square$ Rivers south-east

Figure 1b The senatorial district of Rivers State under consideration. Source: [23]

The population for this study consisted of dewatered cassava mash (DCM) processing centres in Rivers state. 


\subsection{Sampling Method}

A sample of 150 processors were randomly selected, fifty (50) from each of the three senatorial zones of Rivers state, Zone A, representing Rivers West, Zone B, Rivers South-East and Zone C, Rivers East with 30 females and 20 males.

The sample size was obtained using the formula given by [24]:

$\mathrm{n}=\frac{z^{2} p q}{e^{2}}$

where $\mathrm{n}=$ sample size,

$\mathrm{z}=$ level of confidence according to the standard normal distribution (95\%)

$\mathrm{p}=$ population having the characteristics sought,

$\mathrm{q}=1-\mathrm{p}$ and

$\mathrm{e}=$ degree of precision

The sampling procedure adopted was the random technique of sampling whereby members in the population have equal probability of being selected from the three senatorial districts making up Rivers state.

The processors' measured data was used to develop an improved dewatered cassava mash (DCM) sieve that would reduce the level of discomfort in the sieving process as well as enhance productivity. The following materials were used for the measurement of the body parts of cassava processors in the study area: measuring tape, weighing scale, wooden stool, the user group. The parts relating to the sieving machine measured in centimeter [15] were:

C - Shoulder height (sitting)

D - Elbow height (sitting),

E - Lower leg length (popliteal height),

F - Elbow to fingertip,

G - Buttock popliteal length,

H - Thigh clearance,

J - Hip breadth (sitting),

K - Knee height (sitting),

L - Forward grip reach.

These parts were identified from the processors (Figure 2) during the sieving process which highlights the prevalent posture of processors during traditional sieving process. 

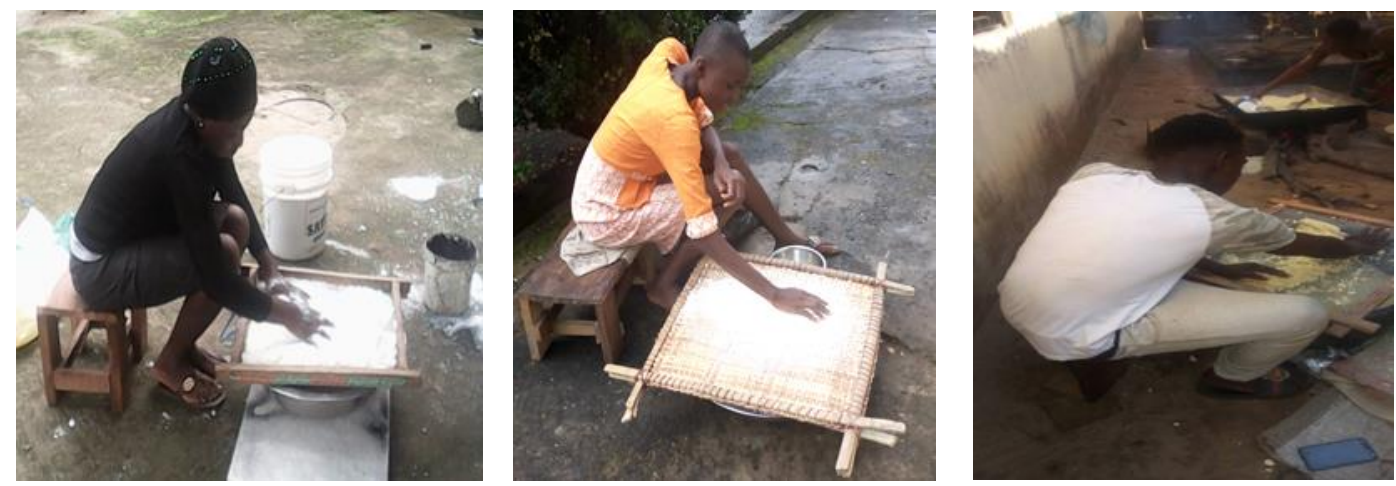

Figure 2 Current postures of a processors using traditional sieve

The measured parts of the processors were adjusted and used for the design of the conceptualized DCM sieving machine in consideration of ergonomic factors as shown in Figure 3.

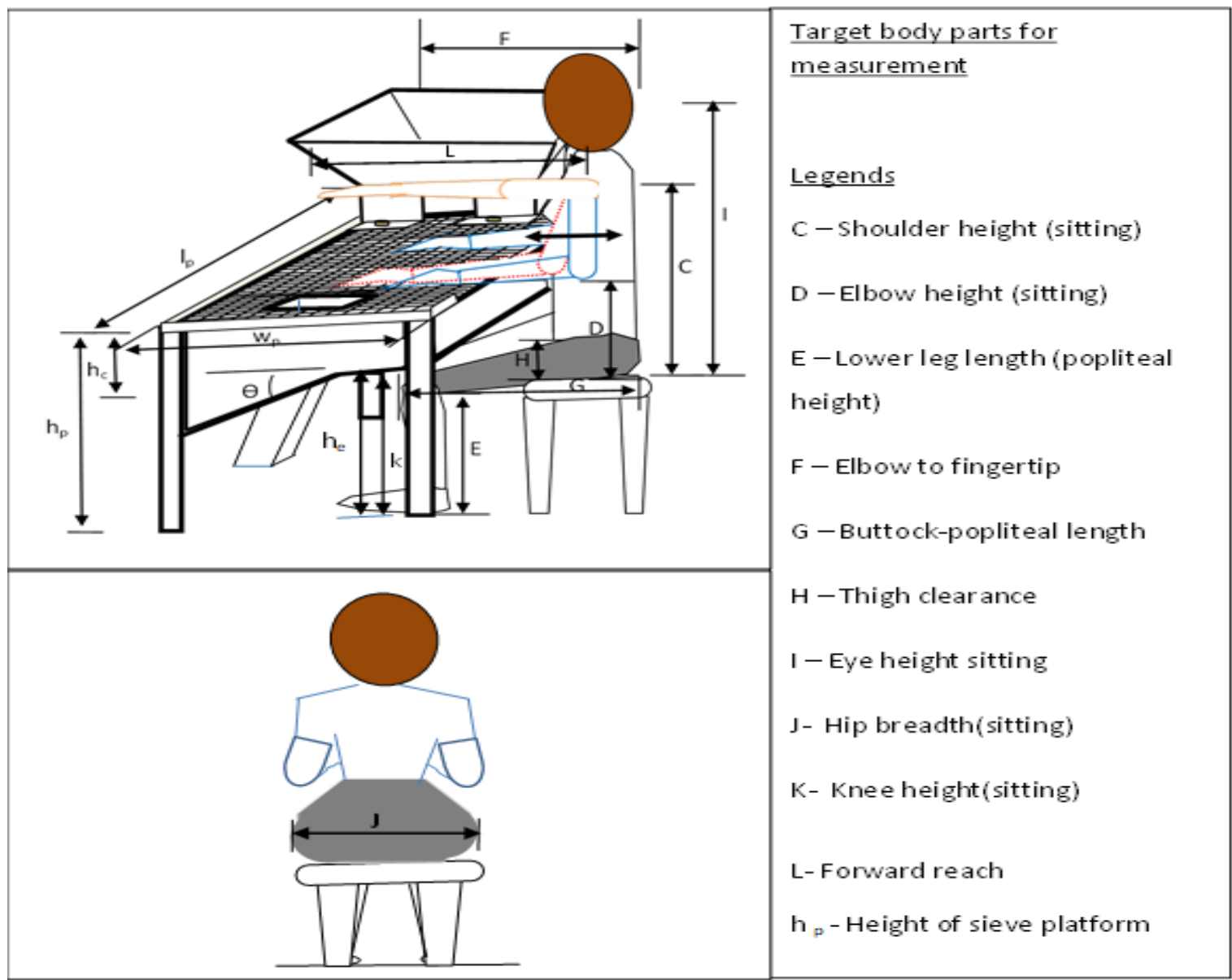

Figure 3 The adjusted posture of a processor in a conceptualized improved manual DCM

Figure 3 show a modification of current postures of processors using traditional sieve through adjustments to their head/neck, shoulder/arm, lower leg/knee/buttock popliteal length and sitting height from an awkward posture to a standard or neutral posture [25], made to limit misfit, initiation, exposure, and sustenance of discomfort [7].

\subsection{Design Consideration}

The following design considerations were made based on the concept in Figure 3: 
- The user's back/neck was designed to remain at a neutral position ( $90^{\circ}$ position) while performing the sieving task instead of being in the bent posture observed in the traditional sieving process to prevent induced stress.

- Shoulder and arm was designed to be at the neutral position, as the arm rests at an angle of $90^{\circ}$ on the sieving platform thus keeping the back in an upright or normal position [25].

- The hopper is on the platform for easy access to DCM to avoid bending at the end of each sieving cycle.

- The coarse particle exit is also on the platform for easy discharge of coarse particles at the end of each sieving cycle.

- The dimension for building the machine was established based on the anthropometry of the user groups to ensure portability, prudent use of material and economy.

- The slope of the undersize exit chamber - angle of repose $(\theta)$ was established using expression: $\theta=\tan ^{-1} 2 h / D$, 2

The angle of repose $\theta$ was obtained by filling a sample of DCM into a cylindrical and inverting the container, allowing the sample from the inverted container to fall by gravity slowly. After four replications, average height of the conical shape of the DCM measured using a metre rule was $8.50 \mathrm{~cm}$ and the average diameter was $19 \mathrm{~cm}$, using equation 2 yielded the angle of repose.

- The sieve was designed to use perforated round hole squared pitch pattern with diameter $5 \mathrm{~mm}$ and between hole spacing of $1 \mathrm{~mm}$ [4]

- Materials for the machine stand and frame was of mild steel while the sieve was of galvanize steel developed with focus on portability, durability, affordability and resistance to rust.

\section{Results and discussion}

The anthropometric data of 150 cassava processors collected from the three research zones and analyzed for the purpose of developing the design dimension for the improved manual DCM sieve are presented in table 1 to table 4

\subsection{Anthropometry of cassava processors in zone A}

Table 1, shows the result of measurement of the body parts of twenty (20) male and thirty (30) female cassava processors in zone A of the three zones under investigation carried out for the purpose of generating data for the design and development of improved manual sieving machine. The parameters measured are shown in column 1 of the table. The last two columns shows the average minimum and maximum values for each parameter measured. For the lower leg length designated "E" in the conceptualized DCM sieving machine for the thirty female processors measured and shown in table 1 , the data range obtained was 37 to $48.7 \mathrm{~cm}$ inclusive. The column under $\min / \mathrm{max}$ in the table shows the average minimum value for the female processors to be 37 whereas the maximum is 48.7 .

Table 1 Statistical analysis of body parts measurement (Zone A)

\begin{tabular}{|l|l|l|l|l|l|l|l|l|l|}
\hline \multicolumn{2}{|l|}{ Parameters } & \multicolumn{4}{l|}{ Men (n= 20) } & \multicolumn{2}{l|}{ Women (n=30) } & \\
\hline Length (cm) & Tag & $5^{\text {th }}$ & $50^{\text {th }}$ & $95^{\text {th }}$ & $5^{\text {th }}$ & $50^{\text {th }}$ & $9^{\text {th }}$ & Min & Max \\
\hline Age & R & 18.5 & 37.5 & 56.5 & 21 & 40 & 58 & 18.5 & 58 \\
\hline Elbow height sitting & $\mathrm{D}$ & 18 & 20.7 & 24 & 19 & 22 & 25 & 18 & 25 \\
\hline Lower leg length & $\mathrm{E}$ & 39 & 45.1 & 48.7 & 37 & 42 & 47 & 37 & 48.7 \\
\hline Elbow to finger tip & $\mathrm{F}$ & 41.8 & 47.7 & 51.3 & 42 & 47 & 52 & 41.8 & 52 \\
\hline Buttock popliteal length & $\mathbf{G}$ & 45.3 & 54.8 & 63 & 45 & 54 & 63 & 45 & 63 \\
\hline Thigh clearance & H & 10 & 12.5 & 16 & 11 & 14 & 17 & 10 & 17 \\
\hline Hip breadth & $\mathrm{J}$ & 31 & 35.5 & 46 & 30 & 34 & 45 & 30 & 46 \\
\hline Knee height sitting & $\mathrm{K}$ & 49 & 53.1 & 57 & 48 & 51 & 52 & 48 & 57 \\
\hline Forward grip reach & $\mathrm{L}$ & 69 & 79.5 & 82.5 & 68 & 77 & 82 & 68 & 82.5 \\
\hline
\end{tabular}

The $3^{\text {rd }}$ to $8^{\text {th }}$ columns of the table shows the record of computed $5^{\text {th }}, 5^{\text {th }}$ and $95^{\text {th }}$ percentile for both the male and female processors. For the male processors, the data under parameter E are 39, 45.1 and 48.7 whereas for the female 
processors these are: 37,42 and 47 for the reference percentiles respectively. The results of data from the measurement of the rest of the parameters in the table were similarly computed and recorded.

From the table 1, it was observed that the data obtained under the measured parameters for the males were different from those obtained for the female processors. The data were therefore analyzed using excel t-test to ascertain if the difference observed were statistically significant with results obtained showing a t-stat values of $0.0079,0.067$ and 0.048 at 16 degree of freedom, $5 \%$ significant level with a t-critical value of 2.12 for the $5^{\text {th }}, 50^{\text {th }}, 95^{\text {th }}$ percentile respectively. It was found from this result that there was no statistically significant difference between the measured parameters for males and for female processors in zone A, suggesting that either of the data could be used for developing the sieving machine, with a comfortable fitting for both genders. The age range in this zone was 18 to 58 years.

\subsection{Anthropometry of cassava processors in zone B}

Table 2, shows the result of measurement of twenty (20) men and thirty (30) women cassava processors in zone B and the statistical analysis of the mean value of the measured data in percentile as well as minimum and maximum dimensions. The age range in this zone was 19 to 59.5 years.

Table 2 Statistical analysis of body parts measurement (Zone B)

\begin{tabular}{|l|l|l|l|l|l|l|l|l|l|}
\hline & \multicolumn{4}{|l|}{ Men (n= 20) } & \multicolumn{2}{l|}{ Women (n=30) } & & \\
\hline Parameter (cm) & Tag & $5^{\text {th }}$ & $50^{\text {th }}$ & $95^{\text {th }}$ & $5^{\text {th }}$ & $50^{\text {th }}$ & $9^{\text {th }}$ & Min & Max \\
\hline Age & R & 20.5 & 40 & 59.5 & 19 & 37 & 55 & 19 & 59.5 \\
\hline Elbow height sitting & D & 13 & 18 & 22 & 12 & 17 & 21 & 12 & 22 \\
\hline Lower leg length & E & 35.4 & 40 & 48.9 & 36 & 41 & 50 & 35.5 & 50 \\
\hline Elbow to finger tip & F & 36 & 48 & 52 & 38 & 49 & 53 & 36 & 53 \\
\hline $\begin{array}{l}\text { Buttock popliteal } \\
\text { length }\end{array}$ & G & 42 & 48 & 54 & 40 & 46 & 52 & 40 & 54 \\
\hline Thigh clearance & H & 10.5 & 14 & 21 & 11 & 15 & 22 & 10.5 & 22 \\
\hline Hip breadth & J & 26 & 29 & 39 & 27 & 30 & 40 & 26 & 40 \\
\hline Knee height sitting & K & 44 & 49 & 53 & 45 & 50 & 54 & 44 & 54 \\
\hline Forward grip reach & L & 62 & 68 & 73 & 60 & 66 & 71 & 60 & 73 \\
\hline
\end{tabular}

The dimensions sought, for developing the improved sieving machine under the designations: D, E, F , G, H, J , K in the conceptualized dimension are clearly shown in table 2 . The calculated value of the data in terms of $5^{\text {th }}, 50^{\text {th }}$, and $95^{\text {th }}$, percentile for men processors was compared to that of the women processors through excel statistical t-test with the following results: $t$-stat $=0.020,0.043$ and 0.062 for $5^{\text {th }}, 50^{\text {th }}$, and $95^{\text {th }}$ percentile respectively with a t- critical of 2.12 at $5 \%$ significance level. The result showed that there was no significant difference in the measured values for men and that of the women processors, suggesting that either of the values can be used to develop a fitting machine for both genders.

\subsection{Anthropometry of cassava processors in zone $\mathrm{C}$}

Table 3, shows the result of measurement of body dimension of twenty (20) men and thirty (30) women cassava processors in zone $\mathrm{C}$ and the statistical analysis of the mean value of the measured data in percentile as well as the minimum and maximum dimensions. The age range in this zone was 20 to 55 years. 
Table 3 Statistical analysis of body parts measurement (Zone C)

\begin{tabular}{|l|l|l|l|l|l|l|l|l|l|}
\hline & \multicolumn{4}{|l|}{ Men (n= 20) } & \multicolumn{3}{l|}{ Women (n=30) } & & \\
\hline Parameter & Tag & $5^{\text {th }}$ & $50^{\text {th }}$ & $95^{\text {th }}$ & $5^{\text {th }}$ & $50^{\text {th }}$ & $95^{\text {th }}$ & Min & Max \\
\hline Age & R & 22 & 38.5 & 55.2 & 20 & 36 & 54 & 20 & 55 \\
\hline Elbow height sitting & D & 14 & 19 & 22 & 13 & 17 & 20 & 13 & 22 \\
\hline Lower leg length & E & 42 & 47 & 49 & 40 & 45 & 47 & 40 & 49 \\
\hline Elbow to finger tip & F & 37 & 49 & 54 & 35 & 47 & 53 & 35 & 54 \\
\hline Buttock popliteal length & G & 41 & 49 & 57 & 40 & 48 & 56 & 40 & 57 \\
\hline Thigh clearance & H & 9 & 13 & 17 & 9 & 13 & 16 & 9 & 17 \\
\hline Hip breadth & J & 28 & 34 & 41 & 27 & 32 & 40 & 27 & 41 \\
\hline Knee height sitting & K & 45 & 52 & 58 & 43 & 50 & 56 & 43 & 58 \\
\hline Forward grip reach & L & 61 & 67 & 71 & 59 & 67 & 70 & 59 & 71 \\
\hline
\end{tabular}

The dimensions sought, for developing the improved sieving machine under the designations: D, E, F , G, H, J , K and L in the conceptualized dimension are clearly shown in the table. The calculated value of the data in terms of $5^{\text {th }}, 50^{\text {th }}$, and 95th , percentile for men processors was compared to that of the women processors through excel statistical t-test with the following results: $\mathrm{t}$-stat $=0.189,0.187$ and 0.163 for $5^{\text {th }}, 50^{\text {th }}$, and $95^{\text {th }}$ percentile respectively with a $\mathrm{t}$ - critical of 2.12 at $5 \%$ significance level. The result also showed that there was no significant difference in the measured values for men and that of the women processors, suggesting that either of the values could be used to build a fitting machine for both genders.

From tables 1 to 3 , it was observed that the data obtained under the measured parameters from zones $\mathrm{A}, \mathrm{B}$ and $\mathrm{C}$ differs from each other. The data from the three zones were therefore analyzed using analysis of variance ANOVA to ascertain if the difference were statistically significant with respect to the $5^{\text {th }} 50^{\text {th }}$ and $95^{\text {th }}$ percentile male and female processors across the three zones. The F values for the analysis of variance were: $0.103,0.092$ and 0.053 for data on $5^{\text {th }}, 50^{\text {th }}$ and $95^{\text {th }}$ percentile male processor respectively whereas the $\mathrm{F}$ values for female processors were: $0.15,0.99$ and 0.082 with $\mathrm{F}$ crit of 3.40 for the $5^{\text {th }}, 50^{\text {th }}$ and $95^{\text {th }}$ percentile respectively. It was found from this analysis that there is no statistical significant difference in the anthropometry of processors across the three zones.

These findings show that data from any of the three zones can be used to construct befitting sieving machines that can accommodate both male and female processor in the three zones.

\subsection{Establishing the design dimension}

The established designed dimensions for developing the improved sieving machine are shown in table 4. The table shows how the data from the measured part of the processors were used singly or combined to established the designed dimension of the improved manual sieving machine. The first column of the table shows the parts of the improved machine that required dimensioning while the second column shows the measured part that provided data for the dimensions singly or combined. 
Table 4 Recommended dimension for development of improved DCM sieve

\begin{tabular}{|c|c|c|c|}
\hline $\begin{array}{l}\text { Machine parts } \\
\text { to be be } \\
\text { dimensioned }\end{array}$ & $\begin{array}{l}\text { Processor's parts } \\
\text { singly or combined } \\
\text { measured }\end{array}$ & $\begin{array}{l}\text { Designed dimension } \\
\text { (cm) established }\end{array}$ & Dimension source \\
\hline Sitting height & Lower leg length (E) & $\begin{array}{l}\text { An adjustable seat of } \\
\text { height range }(35-50)\end{array}$ & $\begin{array}{l}\text { 5th percentile men- } \\
95 \text { th percentile } \\
\text { women zone B }\end{array}$ \\
\hline Task height hp & $\begin{array}{l}\text { Lower leg length }+ \\
\text { Elbow height sitting } \\
(\mathrm{E}+\mathrm{D})\end{array}$ & 72 & $\begin{array}{l}\text { 95th percentile E } \\
\text { (women) }+95 \text { th } \\
\text { percentile D (men) } \\
\text { zone B }\end{array}$ \\
\hline $\begin{array}{l}\text { Machine width } \\
\text { Wp }\end{array}$ & Elbow to fingertip (F) & 53 & $\begin{array}{l}\text { 95th percentile } \mathrm{F} \\
\text { (women) zone C }\end{array}$ \\
\hline $\begin{array}{l}\text { Machine length } \\
\text { Lp }\end{array}$ & $\begin{array}{l}\text { Hip breadth } \\
(\mathrm{J} \times 2)\end{array}$ & 68 & $\begin{array}{l}50 \text { th percentile Jx2, } \\
\text { women zone B }\end{array}$ \\
\hline Leg entrance $h_{e}$ & $(E+H)$ & 64 & $\begin{array}{l}\text { 50th percentile E } \\
\text { and 95th } \mathrm{H} \text { (men) } \\
\text { Zone C. }\end{array}$ \\
\hline $\begin{array}{l}\text { Collector } \\
\text { chamber } \mathrm{h}_{\mathrm{c}}\end{array}$ & $h_{c}=D-H$ & 16 & $\begin{array}{l}\text { 95th percentile D } \\
\text { (Female) zone A - } \\
\text { 5th percentile H } \\
\text { (male) }\end{array}$ \\
\hline
\end{tabular}

The $3^{\text {rd }}$ column shows a corresponding dimension for the machine parts while the $4^{\text {th }}$ column shows how the established dimensions were developed.

\subsection{Sitting height}

From the table, an adjustable seating height range of 35 to $50 \mathrm{~cm}$ is considered to accommodate variation of users in the study group and enable their part to be oriented to make the processors comfortable while using the machine.

\subsection{Task height hp (machine height)}

Since the task height is not to be adjustable, the $95^{\text {th }}$ percentile $\mathrm{E}$ of women in zone $\mathrm{B}$ which is $50 \mathrm{~cm}$ and $95^{\text {th }}$ percentile $\mathrm{D}$ men in zone $\mathrm{B}$ which is $22 \mathrm{~cm}$ will give a task height of $72 \mathrm{~cm}$ to accommodate the users group.

\subsection{Machine width (Wp)}

$\mathrm{F}$ is the maximum extent the wrist/arm would move during the sieving process. The machine width is set at $95^{\text {th }}$ percentile of $\mathrm{F}$ in zone $\mathrm{C}$ which is $54 \mathrm{~cm}$.

\subsection{Machine length Lp}

For the machine to be of portable length, consideration was given to the space that can be accommodated by hip breadth of the user. Multiplying the $50^{\text {th }}$ percentile hip breadth $(\mathrm{J})$ of women in zone A by 2 will give a comfortable economic length of $68 \mathrm{~cm}$.

\subsection{Leg entrance $\left(h_{e}\right)$}

The leg entrance is the distance between the ground level and the machine under floor. This was drawn from $95^{\text {th }}$ percentile $\mathrm{E}$ and $\mathrm{H}$ of zone $\mathrm{A}$ which is 47 and 17 given a dimension of 64 . 


\subsection{Height of collection chamber $\left(h_{c}\right)$}

The depth of collection chamber of the machine $\left(h_{c}\right)$ was established from the measured value of elbow height (D) minus thigh clearance $(H), h_{c}=D-H$ which gave $16 \mathrm{~cm}$. This was drawn from $95^{\text {th }}$ percentile D (Female) zone A $-5^{\text {th }}$ percentile $\mathrm{H}$ (male) zone $\mathrm{C}$.

The anthropometric data obtained from the three senatorial zones in Rivers state is closely related to those obtained by $[15,26,15]$ Carried out anthropometric studies for designing to fit gari-frying workers in the western states of Nigeria namely: Ogun, Ondo, Ekiti and Lagos state whereas [26] carried out anthropometry in the design of cassava grating machine installation in Niger state of Nigeria. The minimum and maximum, $50^{\text {th }}$ and $95^{\text {th }}$ percentile with respect to hip breadth, forward grip reach, lower leg length (Popliteal height), knee height sitting (cm), buttock popliteal length, elbow height sitting and thigh clearance were closely related to the result of this research. The implication of this result is that the conceptualized improved manual sieving machine developed in this research with its dimensions can be used to develop a real manual sieving machine that can be applied in these areas as well.

\section{Conclusion}

An improved DCM sieve can be developed using the anthropometric parameters of the user groups. There was no statistically significant difference in the measured parameters for male and female processors within and between the zones considered showing that data from either of the zones can be used to develop the improved machine. A proper reorientation of the following measured parameters in the sieving process: lower leg length range, elbow to fingertip, elbow height sitting, thigh clearance and hip bread in consideration of ergonomic, can yield design dimensions for a more comfortable sieving posture for dewatered cassava mash (DCM) sieving machine.

\section{Recommendation}

It is therefore recommended that the following design dimensions in centimeter: processors sitting height range of 35 - 50; sieving task height of 72; Machine width $W_{p}$ of 53; Machine length of 68 obtained from the anthropometry and reorientation of the processors body parts and incorporating a modified sieve of $5 \mathrm{~mm}$ aperture be encouraged as this will initiate a sustainable transformation from the hitherto discomfort prone, slow and energy consuming traditional sieve to an improved method which will enhance the economic viability of cassava farming and processing for the local farmers and product availability for the consumers.

\section{Compliance with ethical standards}

\section{Acknowledgments}

The authors wish to acknowledge the support of Federal College of Education Tech. Omoku, Rivers, Nigeria in providing the enabling environment for carrying out the research.

\section{Disclosure of conflict of interest}

There was no conflict of interest by the authors in the preparation and submission of this paper.

\section{References}

[1] Ahiakwo AA, Isirimah CB, Inimgba DG. Appraisal and projection of dewatered cassava mash sieving technology, Net journal of agric. sc. 2015; 3(2): 55- 59.

[2] Ogunsina BS, Sanni LA, Oladigbo C. Development of a rotary pulverizer for cassava cake in garri production. Journal of food process engrg. 2008; 13(8): 783-797.

[3] Asiru WB, Igbeka JC, Olayanju TMA. Energy expenditure in garri processing activities by Nigerian women. Journal of natural sc., engrg and tech. 2010; 9(2):149-157.

[4] Ahiakwo AA, Simonyan KJ, Eke AB. Effects of sieve aperture modification on dewatered cassava mash sieving process. Nigerian journal of technology (NIJOTECH) 2019; 38 (2): 512 - 519.

[5] Davies RM, Olatunji MO, Burubai W. Survey of cassava processing machinery in oyo state. Intl. journal of agric. Sc.. 2008; 4(3): $337-340$. 
[6] Adekanye TA, Ogunjimi SI, Ajala AO. An assessment of cassava processing plants in Irepodun local government area of Kwara state, Nigeria. World journal of agric. research. 2013; 1(1): 14-17.

[7] Ahiakwo AA, Simonyan KJ, Eke AB. Assessment of workers' level of exposure to work-related musculoskeletal discomfort in dewatered cassava mash sieving process. Arid zone journal of engrg, tech. and environment (AZOJETE). 2019; 15(3): 648 - 661.

[8] Del Prado JL. Anthropometric measurement of Filipino manufacturing workers. International journal of industrial ergonomic. 2007; 37 (6): 497-503.

[9] Dawal SZM, Zadry HR, Azmi SN, Rohim SR, Sartika SJ. Anthropometric database for the learning environment of high school and university students. International journal of occupational safety in ergonomic. 2012; 18(4): 461472 .

[10] Majumder J. Anthropometric dimensions among Indian males - a principal component analysis. Eurasian journal of anthropology. 2014; 5(2): 54-62.

[11] Khaspuri G, Sau S, Dhara P. Anthropometric consideration for designing classroom furniture in rural schools. Journal of human ecology. 2007; 22 (3): 235-244.

[12] Ismail WT, Darshak AD. Anthropometric measurements for ergonomic design of students' furniture in India. International journal of engineering science and technology. 2016; 5(7): 206-217.

[13] McNeill M. Ergonomics in post-harvest agro-processing. African Newsletter on Occupational Health and Safety. 2005; 15(7): 11-13.

[14] Bukola OA, Akinfoye ODA, Olufemi OJ. Comparative assessment of two methods in the production of fermented cassava flour (láfún) on manual energy expended. International journal of agricultural science. 2015; 4(9): 628641.

[15] Samuel TM, Aremu 00, Salami IO, Adetifa BO, Onu LI. Anthropometric studies for designing to fit gari-frying workers. Agricultural engineering international CIGR journal. 2016; 18(1): 180-191.

[16] Anas A, Qutbuddin SM, Hebbal SS, Kumar AC. An ergonomic study of work -related musculoskeletal disorders among the workers working in typical Indian saw mills. International journal of engineering research and development. 2012; 3(9): 38-45.

[17] Guilllermo VV, Leon MM, Simo VA. Development of statistical methodologies applied to anthropometric data oriented towards the ergonomic design of products. PhD thesis, department of statistics and investigation, university of Valencia, Epana. 2014.

[18] Neville S, Alan H, Karel B, Eduardo S, Hal H. Quick exposure checklist (QEC) for the assessment of workplace risks for work-related musculoskeletal disorders (WMSDS) Handbook of human factors and ergonomics methods. CRC Press, New York. 2005.

[19] Surabbi S, Renu A. Ergonomic intervention for preventing musculoskeletal disorders among farm women. Journal of agricultural science. 2010;1(2): 61-71.

[20] Alan H. Handbook of human factors and ergonomics methods, CRC press New York Washington D.C. 2005.

[21] National Population Commission (NPC) and National Bureau of Statistics Estimates. 2016

[22] Map of Nigeria, showing the states, (C) 2014 [updated, Nov, 2014]. Available from https://www.mapsofworld.com

[23] Nkakini So. Agricultural machinery use-management in River state. European journal of engineering and technology. 2019: 7(3): $56-68$.

[24] Susan R, Nigel S, Ana IC. Management research: applying the principles, routledge publishers, London, UK. 2015.

[25] Sandip BW, Manish KB. An Ergonomics intervention in a transformer manufacturing industry to improve productivity. Journal of mechanical and civil engineering. 2014; 52-57.

[26] Jonathan JS, Shehu A. Anthropometry in engineering design (a case study of cassava grating machines installed in doko and kutigi metropolis of lavun local government areas of Niger state). The Nigerian academic forum. 2012; 22(1):132-139. 